\title{
Understanding Educational and Occupational Choices
}

\author{
Jacquelynne S. Eccles*
}

University of Michigan

I am delighted to write the commentary for this very rich set of papers. It is wonderful to have such a diverse set of papers together in one volume. When I began my work on this topic in the mid 1970s, the focus in the field was entirely on the underrepresentation of women in science, technology, engineering, and mathematics, the theoretical tools were quite limited, and the scholars were all of European-American heritage. These papers illustrate how far this area of study has advanced along each of these dimensions.

In 1977, the National Institute of Education put out a call for proposals to study the underrepresentation of women in mathematics based on the findings of Lucy Sells. Dr. Sells had shown that girls in the United States were less likely to take advanced mathematics in high school and that taking advanced mathematics courses was a critical step in the pipeline toward careers in mathematics and science. My colleagues and I put together a theoretical model (the updated version of which is illustrated in Figure 1) as a foundation for our research proposal. We had two goals in developing this model: (1) to focus on choice rather than deficits by asking the question "why were women making the educational and occupational choices they did" rather than the question "why aren't women making the same choices as men"; and (2) to develop a theoretical model that took both personal agency and social/cultural structures into account. The model was grounded in my training as a social-cognitive motivational psychologist, a developmental psychologist, and my growing identification as a feminist psychologist, hence the emphasis both on expectancies and subjective task values as core psychological influences on educational and occupational choices and on social roles and socialization processes as key influences on the ontogeny of individual and group differences in expectancies and task values. My colleagues and I stressed the importance of what we labeled subjective task value, which we proposed is the joint function of several other

\footnotetext{
* Correspondence concerning this article should be addressed to Jacquelynne S. Eccles, Department of Psychology and Education, University of Michigan, 5118 ISR, 426 Thompson Street, Ann Arbor, MI 48197 [e-mail: jeccles@umich.edu].
} 


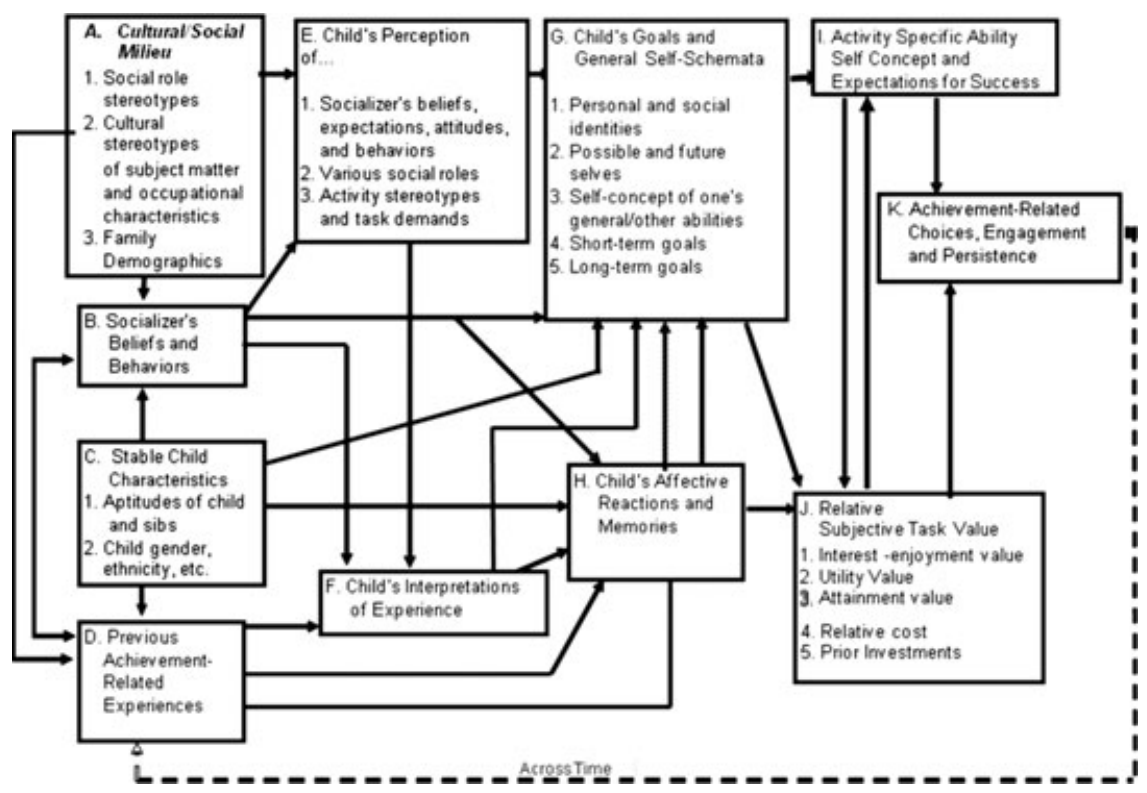

Fig. 1. Updated Eccles et al. socioculturally embedded expectancy value model of achievement choices. (Copyright Jacquelynne S. Eccles.)

motivational beliefs including anticipated interest likely to be experienced in, the attainment and utility value of, and the anticipated psychological, economic and social costs of various possible task or activity choices. We also stressed that each choice is based on the relative subjective task values and expectations for success across the variety of perceived possible options at the time. Third, we stressed the need to take into account the role that social structures/culture/social class play in determining the range of options individuals can and do consider as they make educational and occupational decisions. Finally, we stressed the idea that the hierarchies of the subjective task values of various options are directly influenced by the immediate social context and the developmental stage of the individual making the choice. Thus we stressed the need for a quite general developmental approach to the issue of disparities in science, technology, engineering, and mathematics (STEM). We felt it was critical to understand the "roads taken" to understand the "roads not taken." We stressed that the question of "why women and minorities were less like to aspire to and enter STEM fields than white males and Asians" is best thought of as a subset of the more general question "why does anyone do anything." These same themes are evident in the papers in this issue-most clearly in Syed, Azmitia, and Cooper (2011), Chemers, Zurbriggen, Syed, Goza, and Bearman (2011), Smart Richman, vanDellen, and Wood (2011), London, 
Rosenthal, and Gonzalez (2011), Witkow and Fuligni (2011), Arora, Schneider, Thal, and Meltzer (2011), and Phinney, Torres Campos, Kallemeyn, and Kim (this issue).

At the time we developed this model, there was very little interest in developmental and social psychology in any social roles other than gender and that interest focused primarily on very early development. One of the most striking characteristics of the papers in this issue is how much broader and more sophisticated the authors' approach to social identities and sociocultural processes is now than it was then. For example, Smart Richman et al. (2011) discuss the importance of social identity threats to performance and well-being. This paper illustrates how the field has a much better understanding of the links between social identity processes, contextual cues, and actual performance. We would consider these processes as part of the link between social settings and the anticipated cost of task involvement. An even broader view of the many ways in which personal and social identities relate to academic success of underrepresented ethnic minorities is provided by the papers by Syed et al. (2011), Chemers et al. (2011), and Witkow and Fuligni (2011). Equally striking is the progress that has been made in designing well grounded and effective intervention strategies for both high school and college students. This is evident in the all of the papers in Section III, Institutional Efforts: Barriers and Opportunities, and Section IV, Intervention Strategies: Aligning Ambitions and Mentoring, of the issue.

Finally, these papers provide very concrete evidence of how persistent the problems underlying disparities in participation have been. As noted by Syed and Chemers (2011), although we have seen some increases in the proportion of women in STEM fields, particularly in those linked to the medical, biological, and social sciences, the underrepresentation of women in the physical sciences, engineers, information technology, and other fields of technology persists. There has been even less progress in recruiting students of color into these fields. On the one hand, these articles make it clear that we now have very powerful theoretical and intervention tools to address these disparities at several points in the pipeline. On the other hand, to the extent that both personal and collective or social identities explain group differences in both STEM aspirations and persistence, these papers also make it clear that reducing these disparities will require us to change the stereotypes regarding both the subjective task value and perceived costs of preparing oneself for participation in STEM professions and the stereotypes of STEM professions themselves. The complexity of these transformations is made particularly clear in the articles stressing the role of both personal and contextual social supports in helping URM and women to consider STEM professions as a serious and attainable option and then to support their exploration of and training for STEM careers in both secondary and tertiary educational setting. These points are best illustrated in the articles of Witkow and Fuligni (2011), Hurtado et al. (2011), Arora et al. (2011), Phinney et al. (2011), and Blake-Beard, Bayne, 
Crosby, and Muller (2011). We would classify such interventions under the interplay between identity-based processes and the perceived attainment and utility values and perceived costs of aspiring to and then training oneself to enter STEM professions.

The papers also illustrate the methodological gains that have been made in studying the subtle psychological and social processes underlying the association of identities processes with task choice and performance. This is best illustrated in the papers by Smart Richman et al. (2011) and London et al. (2011), both of which provide examples of relative new methods for studying the link between identity processes and both task choice and performance. I particularly like the experience sampling methodology method discussed by London et al. (2011). This method yields a rich set of information on the day-to-day affective experiences related to STEM and non-STEM activities. Coupling this method with developmental changes in aspirations and course choices provides an excellent way to look at the mediating role of affective memories, the perceived interest value of, and the anticipated emotional costs of STEM versus non-STEM activities in task choice.

In closing, I would like to note that each of these papers illustrates the importance of both social and psychological processes in the ontogeny of career development. Although the papers focus most directly on the career selection processes linked to STEM, the processes discussed contribute broadly to our fundamental understanding of career choice. Developmental and social psychologists have paid relatively little attention to ontogeny of career choice, despite the fact that educational and occupational choices have a major influence on all aspects of life-span development. These papers provide a model of how we can study the confluence of both psychological and social process in the ontogeny of such central, life-defining choices. They also illustrate the importance of looking at the social and psychological influences on the subjective task values of various options as carefully as we have looked at the influences on self-efficacy and expectations for success for various options.

\section{References}

Arora, V., Schneider, B., Thal, R., \& Meltzer, D. (2011). Design of an intervention to promote entry of minority youth into clinical research careers by aligning ambition: The TEACH (Training Early Achievers for Careers in Health) research program. Journal of Social Issues, 67(3), 580-598.

Blake-Beard, S., Bayne, M. L., Crosby, F. J., \& Muller, C. B. (2011). Matching by race and gender in mentoring relationships: Keeping our eyes on the prize. Journal of Social Issues, 67(3), $622-643$.

Chemers, M. M., Zurbriggen, E. L., Syed, M., Goza, B, K., \& Bearman, S. (2011). The role of efficacy and identity in science career commitment among underrepresented minority students. Journal of Social Issues, 67(3), 469-491.

Hurtado, S., Eagan, M. K., Tran, M. C., Newman, C. B., Chang, M. J., \& Velasco, P. (2011) "We do science here": Underrepresented students interactions with faculty in different college contexts. Journal of Social Issues, 67(3), 553-579. 
London, B., Rosenthal, L., \& Gonzalez, A. (2011). Assessing the role of gender rejection sensitivity, identity, and support on the academic engagement of women in non-traditional fields using experience sampling methods. Journal of Social Issues, 67(3), 510-530.

Phinney, J. S., Torres Campos, C. M., Kallemeyn, D. M. P., \& Kim, C. (2011). Processes and outcomes of a mentoring program for Latino college freshmen. Journal of Social Issues, 67(3), 599-621.

Smart Richman, L., vanDellen, M., \& Wood, W. (2011). How women cope: Being a numerical minority in a male-dominated profession. Journal of Social Issues, 67(3), 492-509.

Syed, M. \& Chemers, M. M. (2011). Ethnic minorities and women in STEM: Casting a wide net to address a persistent social problem. Journal of Social Issues, 67(3), 435-441.

Syed, M., Azmitia, M., \& Cooper, C. R. (2011). Identity and academic success among underrepresented ethnic minorities: An interdisciplinary review and integration. Journal of Social Issues, 67(3), $442-468$

Witkow, M. R., \& Fuligni, A. J. (2011). Ethnic and generational differences in the relations between social support and academic achievement across the high school years. Journal of Social Issues, $67(3), 531-552$.

JACQUELYNNE S. ECCLES, the McKeachie/Pintrich Distinguished University Professor of Psychology and Education at the University of Michigan, got her PhD at UCLA in 1974. She has taught at Smith College and the universities of Michigan and Colorado. She is Past President of the Society for Research on Adolescence and Division 35 of the APA, as well as past editor of the Journal of Research on Adolescence and current editor of Developmental Psychology. She has received many awards including lifetime career awards from APS, SRA, SSHD, and Division 15 of the APA and has chaired or co-chaired two international graduate and postgraduate training programs and the MacArthur Research Network for Successful Pathways through Middle Childhood. Her research focuses on: (1) the role that social and personal identities play in individual's life defining decisions and (2) the role of social contexts in human development. 